\title{
A Nonstructural Viral Protein Expressed by a Recombinant Vaccinia Virus Protects against Lethal Cytomegalovirus Infection
}

\author{
STIPAN JONJIĆ,† MARGARITA DEL VAL, GÜNTHER M. KEIL, MATTHIAS J. REDDEHASE, \\ AND ULRICH H. KOSZINOWSKI* \\ Federal Research Centre for Virus Diseases of Animals, D-7400 Tübingen, Federal Republic of Germany
}

Received 30 October 1987/Accepted 29 January 1988

\begin{abstract}
The nonstructural immediate-early protein pp89 of murine cytomegalovirus (MCMV) is the first viral protein synthesized after infection and has a regulatory function in viral gene expression. Despite its localization in the nucleus of infected cells, pp89 is also the dominant antigen recognized by MCMV-specific cytolytic T lymphocytes. The recombinant vaccinia virus MCMV-ieI-VAC, which expresses pp89, was used to study the capacity of this protein to induce protective immunity in BALB/c mice. Vaccination with MCMV-iel-VAC induced a long-lasting immunity that protected mice against challenge with a lethal dose of MCMV but did not prevent infection and morbidity. In vivo depletion of $\mathrm{CD8}^{+} \mathrm{T}$ lymphocytes before challenge completely abrogated the protective immunity. $\mathrm{CDB}^{+} \mathrm{T}$ lymphocytes derived from MCMV-ieI-VAC-primed donors and adoptively transferred into sublethally irradiated and MCMV-infected recipients were found to limit viral replication in host tissues, whereas $\mathrm{CD4}^{+} \mathrm{T}$ lymphocytes and pp89-specific antiserum had no protective effect. The data demonstrate for the first time that a single nonstructural viral protein can confer protection against a lethal cytolytic infection and that this immunity is entirely mediated by the $\mathrm{CD8}^{+}$ subpopulation of $\mathbf{T}$ lymphocytes.
\end{abstract}

Cytomegaloviruses (CMVs) are members of the betaherpes subfamily of the herpesvirus group. In the immunocompetent host, CMV infection is effectively controlled and the virus persists in a latent stage. In the immunocompromised host, however, CMV infection represents a major viral cause of morbidity and mortality (22-24). The analysis of the immune mechanisms operative in the immunocompetent host is a prerequisite to develop specifically designed vaccines. Cellular immunity is involved in the control of CMV infection. It has been suggested that cytolytic $T$ lymphocytes (CTLs) play a pivotal role, since the ability to mount a specific CTL response is inversely correlated with lethal disease, whereas no correlation has been found between remission of CMV disease and CMV-specific antibody titers $(22,27)$.

The infection of mice with the murine CMV (MCMV) serves as a general model for CMV infection. We study the protective function of $\mathrm{T}$ lymphocytes and characterize the viral antigens recognized. Using an adoptive-transfer model, we have determined that specifically sensitized $\mathrm{T}$ lymphocytes that contain the CD8 (Lyt-2)-positive subset limit viral spread, prevent tissue destruction by the virus, and protect against lethal disease $(28,32-34)$. Sensitized CTLs detect both structural and nonstructural viral antigens, and CTLs with specificity for nonstructural antigens expressed during the immediate-early (IE) phase of MCMV replication are the dominant subset $(30,31)$. Within the 235-kilobase-pair double-stranded linear DNA of the MCMV genome (8), abundant IE transcription originates from three transcription units, ie1, ie2, and ie3, located in a region of about 12 kilobase pairs $(12,13)$. Transcription unit ie1, which is under the control of a long and complex enhancer element (7), is predominantly transcribed, and antigens expressed by ie 1 in transfected cells are detected by IE-specific CTLs $(18,20)$.

\footnotetext{
* Corresponding author.

† Present address: Faculty of Medicine, University of Rijeka, 51000 Rijeka, Yugoslavia.
}

Several differently spliced mRNAs are transcribed from ie1 (13). A 2.75-kilobase mRNA transcribed from gene ieI contained in transcription unit iel is translated into a nonstructural regulatory phosphoprotein of 89,000 daltons (Da), the major MCMV IE protein pp89 $(13-15,19)$.

Several different vaccinia recombinant viruses expressing single foreign structural viral antigens have been used as experimental vaccines in a variety of models (for a review, see reference 21). To selectively analyze the role of a nonstructural herpesvirus protein in the induction of protective immunity, we have constructed a recombinant vaccinia virus containing gene ieI of MCMV (42). Infection of cells with the vaccinia recombinant virus leads to expression of the membrane antigen recognized by the IE-specific CTL clone IE1, and infection of mice with the recombinant virus induces pp89-specific CTLs in vivo (42). Here we studied the potential protective effect of the recombinant vaccinia virus when used as an experimental vaccine. We provide the first evidence that immunization against a single nonstructural herpesvirus protein can protect against a lethal course of infection.

\section{MATERIALS AND METHODS}

Mice. Six- to eight-week-old BALB/c mice were bred in our colony under specific-pathogen-free conditions.

Viruses. The Smith strain of MCMV (VR-194; American Type Culture Collection, Rockville, Md.) was used as tissuecultured virus that was propagated in BALB/c mouse embryo fibroblasts (MEFs) and purified as described previously (29). For challenge infection of immunized mice, MCMV salivary gland virus, isolated after three in vivo passages of MCMV in 3-week-old BALB/c mice, was prepared as a $10 \%$ $(\mathrm{wt} / \mathrm{vol})$ homogenate of salivary gland tissue in minimal essential medium. The virus stock contained $10^{7} \mathrm{PFU}$ of MCMV per $\mathrm{ml}$. The construction of the vaccinia recombinant virus containing gene iel of MCMV (MCMV-iel-VAC) has been described previously (42).

Viral sensitization and challenge. Mice were sensitized by 
intravenous (i.v.) injection of $2 \times 10^{7} \mathrm{PFU}$ of MCMV-ieIVAC or wild-type vaccinia virus. Sensitization with MCMV was done by injection of $2 \times 10^{5}$ PFU of tissue-culturegrown virus into one hind footpad. To test protective immunity after vaccination, mice were challenged by intraperitoneal (i.p.) application of the indicated doses of MCMV salivary gland virus (1 $50 \%$ lethal dose $\left[\mathrm{LD}_{50}\right]$ equals $10^{5}$ PFU) (4), and morbidity and mortality were monitored daily for 30 days.

Adoptive T-lymphocyte transfer. To assess the antiviral efficacy of $\mathrm{T}$ lymphocytes, adoptive-transfer experiments were performed essentially as described previously (34). Two hours before cell transfer, recipient mice were subjected to total-body $\gamma$ irradiation with $6 \mathrm{~Gy}$ and infected in one hind footpad with $2 \times 10^{5}$ PFU of tissue-culture-grown MCMV. Donor T lymphocytes were enriched to a purity of more than $95 \%$ by passage through nylon-wool columns. Depletion of the $\mathrm{CD}^{+}$and $\mathrm{CD}^{+}$subsets was achieved by incubation with monoclonal antibodies anti-Lyt-2 (hybridoma YTS-169.4, rat immunoglobulin G2b) (5) and antiL3T4 (hybridoma GK1.5, rat immunoglobulin G2b) (6), respectively, followed by complement treatment (34).

In vivo depletion of the $\mathrm{CD8}^{+} \mathrm{T}$-lymphocyte subset. On the day of challenge with the salivary gland isolate of MCMV, $0.8 \mathrm{mg}$ of monoclonal antibody 169.4 (anti-Lyt-2) (5) contained in $2 \mathrm{mg}$ of protein of partially purified ascites was injected i.v. into vaccinated mice. The efficacy of depletion was repeatedly monitored by cytofluorometric analysis, and the reduction of $\mathrm{CD}^{+} \mathrm{T}$ lymphocytes in spleen and lymph nodes was always found to be at least $99 \%$ (data not shown).

Determination of virus titers in tissue. Titers of infectious MCMV in the spleen were determined 14 days postinfection by a plaque assay as described previously (34). Virus titers $(x$ and $y$ ) were regarded as significantly different for $\boldsymbol{P}$ ( $x$ versus $y$ ) $<\alpha=0.05$ (one sided), where $P$ is the observed probability value and $\alpha$ is the selected significance level (Wilcoxon-Mann-Whitney exact rank sum test).

Detection of virus-specific antibodies. MCMV-specific antibodies were determined by enzyme-linked immunosorbent assay (ELISA), radioimmunoprecipitation, and virus neutralization.

(i) ELISA. Flat-bottom microdilution plates were coated with antigen from MCMV-infected MEFs. Infection of MEFs was performed with a multiplicity of 20 PFU per cell for $24 \mathrm{~h}$. In the late phase of MCMV replication, MEFs were harvested by trypsinization, washed three times in phosphate-buffered saline (PBS), and lysed by ultrasonication. A $0.1-\mathrm{ml}$ portion of cell lysate (equivalent to $10^{5}$ cells) was added to each well, and adsorption was allowed for $12 \mathrm{~h}$ at $4^{\circ} \mathrm{C}$. The excess hinding sites were saturated with $1 \%$ bovine serum albumin in PBS. The plates were then washed in PBS, and $0.1-\mathrm{ml}$ portions of serum dilutions were added to individual wells. After $2 \mathrm{~h}$ of incubation at room temperature, the plates were washed with PBS $-0.05 \%$ Tween $20,0.1 \mathrm{ml}$ of a 1:2,000 dilution of horseradish peroxidase-conjugated goat anti-mouse immunoglobulin $\mathrm{G}$ (heavy and light chains) antibody (TAGO, Burlingame, Calif.) was added to each well, and the plates were kept at room temperature for a further 1 h. After the plates were washed, development with the substrate $o$-phenylenediamine (Sigma Chemical Co., St. Louis, Mo.) was allowed for $20 \mathrm{~min}$ at room temperature. The reaction was stopped with $2 \mathbf{M}$ sulfuric acid, and the optical density at $492 \mathrm{~nm}$ was measured in an ELISA microplate reader. (ii) Radioimmunoprecipitation. Labeling of cells with [ $\left.{ }^{35} \mathrm{~S}\right]-$ methionine, preparation of cell lysates, and immunoprecipitation were carried out as described previously (15).

(iii) Virus neutralization. The titer of MCMV-specific neutralizing antibodies was determined by the plaque reduction assay on MEF monolayers grown in 48-well flat-bottom plates. Sera were serially diluted, and $200 \mu$ l of each dilution was mixed with $25 \mu \mathrm{l}$ of rabbit complement and ca. 100 PFU of MCMV contained in $25 \mu \mathrm{l}$ of medium. The mixture was incubated at $37^{\circ} \mathrm{C}$ for $1 \mathrm{~h}$ before performance of the plaque assay as described previously (34). Control sera positive or negative for antibody to MCMV were included. The titer indicates the serum dilution resulting in $50 \%$ reduction of plaque numbers.

\section{RESULTS}

$\mathrm{CD8}^{+} \mathrm{T}$ lymphocytes sensitized by the nonstructural IE protein pp89 limit MCMV multiplication in host tissue. Previous studies have established that $\mathrm{T}$ lymphocytes of the $\mathrm{CD8}^{+}$subset sensitized in donor mice during infection with MCMV limit virus multiplication in various tissues of infected, immunocompromised recipient mice after adoptive lymphocyte transfer $(28,32,34)$. Furthermore, evidence was provided that this antiviral effect, protection against viral interstitial pneumonia, and survival from MCMV disease can be mediated by a function of $\mathrm{CD}^{+} \mathrm{T}$ lymphocytes specific for IE antigens (33). However, it was unknown whether a protective antiviral immune response can be induced by the nonstructural phosphoprotein pp89 encoded by gene $i e I$, by another IE protein encoded by the IE transcription unit ie 2 or ie3, or by any other product of a differently spliced transcript derived from transcription unit ie1. A role for pp89 in protective immunity could be documented by sensitization of adoptive-transfer donors with the recombinant virus MCMV-ieI-VAC, which contains the intron-free continuous open reading frame of ieI and expresses pp89 exclusively (Fig. 1). This result was not at all clear a priori since the detection of pp89-specific CTL activity after priming with MCMV-ieI-VAC required an in vitro period of restimulation with MCMV (42).

For the relevant negative control, nylon-wool-purified $\mathrm{T}$ lymphocytes derived after priming with wild-type vaccinia virus were transferred (Fig. 1, column A). These cells were not able to control MCMV replication in the spleen of immunocompromised adoptive-transfer recipients, and the virus titer was not different from those observed after no transfer of cells or after transfer of nonprimed $T$ lymphocytes (data not shown). As expected based on a previous study (28), T lymphocytes derived from donors that were latently infected with MCMV effectively limited the spread of MCMV in the spleen (Fig. 1, column B). Potentially, in addition to detecting IE antigens as dominant antigens, the antiviral effector cells in this group could be specific for a multitude of other viral nonstructural as well as structural proteins. Compared with the results for the vaccinia virus control, T lymphocytes sensitized against pp89 expressed by MCMV-ieI-VAC significantly limited MCMV multiplication (Fig. 1, compare columns $A$ and $C, P=0.005$ ). This antiviral function resided within the $\mathrm{CD8}^{+}$subset of MCMV-ieIVAC-primed T lymphocytes (Fig. 1, column D); MCMV-ieIVAC-primed $\mathrm{CD}^{+}{ }^{+} \mathrm{T}$ lymphocytes did not exert an antiviral effect (Fig. 1, column E).

The different efficacy of $\mathrm{T}$ lymphocytes sensitized with whole MCMV and with MCMV-ieI-VAC (Fig. 1, compare columns $B$ and $C$ ) is not surprising since infection with 


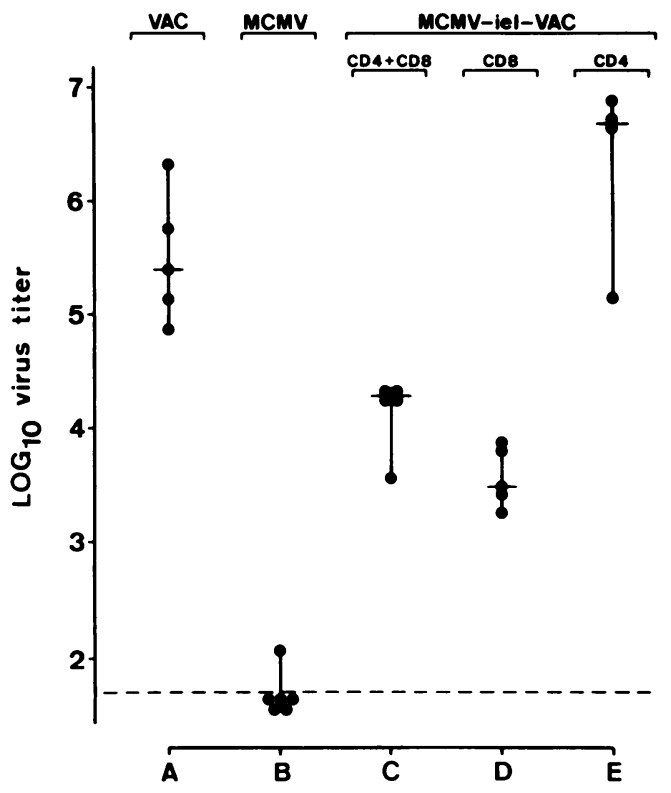

FIG. 1. In vivo antiviral function of MCMV-ieI-VAC-primed T lymphocytes. The in vivo antiviral efficacy of sensitized $T$ lymphocytes was tested by adoptive lymphocyte transfer. Throughout the experiment, $2 \times 10^{5}$ nylon-wool-purified $\mathrm{T}$ lymphocytes derived from spleens and lymph nodes of immunized mice were transferred i.v. into irradiated, infected recipient mice. Virus titers in the spleens of the recipients were determined at day 14 postinfection. Individual titers are signified by closed circles, and median values are indicated by horizontal lines. The broken line represents the detection level, which was 50 PFU of MCMV. Columns: A, T lymphocytes derived from mice immunized i.v. with $2 \times 10^{7}$ PFU of wild-type vaccinia virus (VAC) 21 days earlier; B, T lymphocytes derived from latently infected mice 4 months after intraplantar infection with $2 \times 10^{5}$ PFU of MCMV; C, T lymphocytes derived from mice immunized i.v. with $2 \times 10^{7}$ PFU of MCMV-iel-VAC recombinant virus 21 days earlier; $D, T$ lymphocytes of group $C$ depleted of the $\mathrm{CD}^{+}$subset; $\mathrm{E}$, T lymphocytes of group $\mathrm{C}$ depleted of the $\mathrm{CD8}^{+}$subset.

vaccinia virus generates a strong vaccinia virus-specific T-lymphocyte response that can be demonstrated directly without in vitro restimulation (17), whereas only a minor fraction of the sensitized $\mathrm{T}$ lymphocytes is directed against the insert gene product and can be disclosed only upon in vitro selection by restimulation with the parent virus of the insert (42).

The data positively document for the first time that $\mathrm{CD}^{+}$ $T$ lymphocytes sensitized by a single nonstructural, regulatory protein of MCMV, the IE protein $\mathrm{pp} 89$, limit virus multiplication in host tissue.

MCMV-ieI-VAC protects mice against challenge infection with a lethal dose of MCMV. When testing a single viral gene product for its potential use as a vaccine, it is a conditio sine qua non to prove that immunity elicited by the candidate protein is sufficient for protection. We therefore compared the protective potential of vaccination with MCMV-ieI-VAC with that of vaccination with a nonlethal dose of MCMV (Fig. 2). Three weeks after vaccination, a challenge infection was initiated by i.p. application of $5 \mathrm{LD}_{50} \mathrm{~s}$ of the highly virulent salivary gland isolate of $\operatorname{MCMV}(11,25)$. Nonimmunized mice and those immunized with wild-type vaccinia virus died of acute MCMV disease within 6 to 8 days postchallenge. After vaccination with the infectious, tissueculture-attenuated isolate of MCMV all mice survived (Fig.

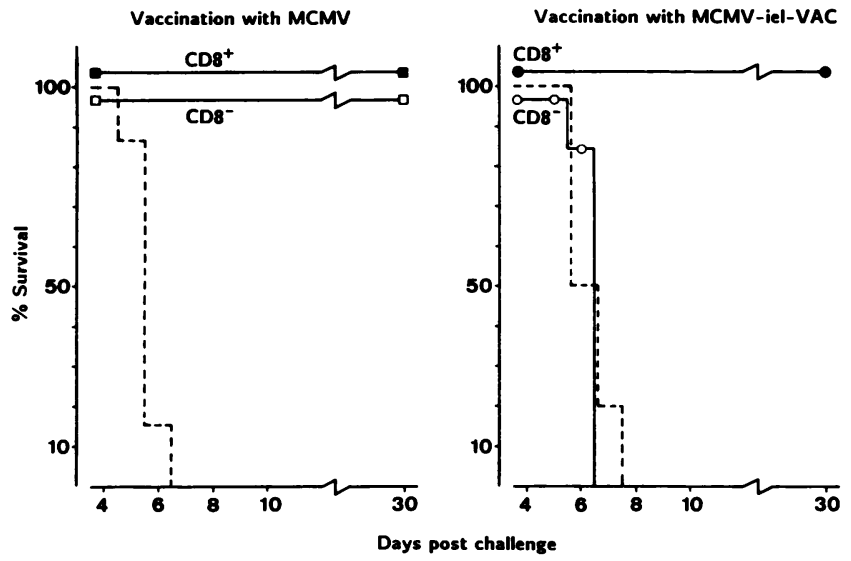

FIG. 2. Protection against challenge infection. Groups of 6 to 10 mice were immunized, as indicated in the legend to Fig. 1, 21 days before an i.p. challenge infection with $5 \mathrm{LD}_{50} \mathrm{~s}$ of the salivary gland isolate of MCMV. (Left panel) No immunization (- - - ), vaccination with MCMV ( $\mathbb{0}$ ), or vaccination with MCMV and in vivo depletion of $\mathrm{CD8}^{+} \mathrm{T}$ lymphocytes on the day of the challenge ( $\square$ ). (Right panel) Immunization with wild-type vaccinia virus (-- - ), vaccination with MCMV-iel-VAC (0), or vaccination with MCMViel-VAC and in vivo depletion of $\mathrm{CD8}^{+} \mathrm{T}$ lymphocytes on the day of the challenge $(O)$.

2 , left panel). The protection was still effective when on the day of challenge infection, $\mathrm{CD}^{+} \mathrm{T}$ lymphocytes were depleted in vivo by infusion of antibodies against the CD8 antigen, indicating that protection was not, or at least not only, mediated by antiviral $\mathrm{T}$ lymphocytes of the $\mathrm{CD}{ }^{+}$ subset. Vaccination with MCMV-ieI-VAC also provided protection (Fig. 2, right panel), but this protection was completely dependent upon the presence of $\mathrm{CD}^{+} \mathrm{T}$ lymphocytes. It should be noted that in four experiments the survival rate of mice immunized with MCMV-ieI-VAC varied between 50 and $100 \%$, with an average of $71 \%$. Vaccination with MCMV-ieI-VAC did not prevent infection and morbidity: all individuals developed lethargy, hunching, and a wasting syndrome, as did nonimmunized mice. By day 7 postchallenge, however, MCMV-iel-VAC-primed mice were recovering, whereas the nonimmune controls all died of MCMV disease. In essence, pp89 induced a protective immunity mediated by $\mathrm{CD}^{+} \mathrm{T}$ lymphocytes that protected against a lethal course of disease.

Vaccination with whole MCMV induces protective antibodies. It became apparent from the vaccination-challenge experiments that protection by MCMV-ieI-VAC is entirely based on $\mathrm{CD}^{+} \mathrm{T}$ lymphocytes, whereas vaccination with

TABLE 1. Antibody response to MCMV and MCMV-ieI-VAC

\begin{tabular}{lclcc}
\hline Sensitization & $\begin{array}{c}\text { ELISA } \\
\text { titer }^{\prime \prime}\end{array}$ & $\begin{array}{c}\text { Immuno- } \\
\text { precipitation of } \\
\text { MCMV proteins }\end{array}$ & $\begin{array}{c}\text { Neutrali- } \\
\text { zation of }_{\text {virus }}{ }^{a}\end{array}$ & $\begin{array}{c}\text { Protective } \\
\text { effect }^{b} \\
\text { (survivors/ } \\
\text { total) }\end{array}$ \\
\hline MCMV & 512 & $\begin{array}{c}\text { 89-kDa and } \\
\text { several others }\end{array}$ & 40 & $6 / 6$ \\
MCMV-iel-VAC & 512 & $\begin{array}{l}\text { 89-kDa } \\
\text { None }\end{array}$ & $<2$ & $0 / 7$ \\
Vaccinia virus & $<2$ & $<2$ & $0 / 7$ \\
\hline
\end{tabular}

" Reciprocal of serum dilution giving half-maximum activity.

b Mice were passively immunized with $0.5 \mathrm{ml}$ of pooled serum samples from five mice immunized 3 to 4 weeks earlier and were challenged 2 h later with 5 $\mathrm{LD}_{\mathrm{s0}} \mathrm{s}$ of the salivary gland isolate of MCMV. 
MCMV induces an additional protective mechanism (Fig. 2). We therefore analyzed and compared the antibody responses after immunization with MCMV and MCMV-ieIVAC (Table 1).

Sera were assayed by ELISA, immunoprecipitation, and neutralization in vitro. Serum samples from both MCMVinfected mice and mice primed with MCMV-ieI-VAC had comparable antibody titers in the ELISA. They differed, however, when the ability to precipitate MCMV proteins was tested. MCMV immune serum immunoprecipitated several polypeptides from MCMV-infected MEFs, including an 89-kDa protein, whereas serum from MCMV-ieI-VACprimed mice precipitated only an $89-\mathrm{kDa}$ protein indistinguishable from pp89 (15). A neutralizing antibody titer was detected in MCMV immune serum whereas no neutralizing activity was present in sera from MCMV-ieI-VAC- or wildtype vaccinia virus-primed mice. Absence of neutralization in vitro, however, does not exclude protective effects of antiserum in vivo where infected cells with surface-bound antibodies could be eliminated by cellular mechanisms. Thus, to determine whether antibodies induced by MCMV or MCMV-ieI-VAC protect mice against challenge infection, mice were passively immunized by serum transfer (Table 1). All mice that received MCMV immune serum survived the challenge, whereas mice that received sera from MCMV-ieIVAC- or wild-type vaccinia virus-primed mice died within 7 days. This demonstrated that pp89-specific antibodies generated after infection with MCMV-ieI-VAC neither neutralize MCMV in vitro nor protect against lethal MCMV challenge in vivo and, on the other hand, strongly suggested that antibodies specific for other viral proteins contributed to the protection seen after vaccination with MCMV. It must be noted, however, that there is no correlation between serum antibody titers and the capacity to clear virus from infected tissues (33).

Longevity of protection induced by MCMV-iel-VAC. Evidence presented so far demonstrates that protection by the experimental vaccine was solely based upon the generation of a cellular immune response, with $\mathrm{T}$ lymphocytes of the $\mathrm{CD}^{+}$phenotype representing the antiviral effector cells. This mode of protection is different from the protective principle of vaccines presently used, which depend upon the induction of a long-lasting neutralizing antibody response. It was therefore important to test whether MCMV-ieI-VAC could induce a lasting protective immunity. To address this question, mice from the batch characterized by the data shown in Fig. 2 were challenged with a lethal dose of the salivary gland isolate of MCMV at 4 months after vaccination. The results (Table 2) document the enduring protective effect of the experimental vaccine.

\section{DISCUSSION}

We tested the protective effect of a recombinant vaccinia virus expressing the nonstructural regulatory IE protein

TABLE 2. Long-lasting protective immunity after vaccination with MCMV-ieI-VAC ${ }^{a}$

\begin{tabular}{|c|c|}
\hline Sensitization & Survivors $(n=6)$ \\
\hline MCMV-ieI-VAC. & 6 \\
\hline Vaccinia virus ..... & 0 \\
\hline 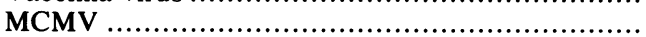 & 6 \\
\hline 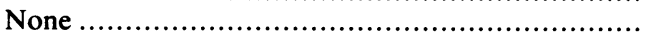 & $\mathbf{0}$ \\
\hline
\end{tabular}

a Four months after vaccination, mice were challenged i.p. with $2.5 \mathrm{LD}_{50} \mathrm{~s}$ of the salivary gland isolate of MCMV. pp89 of MCMV and report three findings: (i) vaccination protected the animals against mortality but not against infection and morbidity after challenge with a lethal dose of MCMV, (ii) the protective effect was long lasting, and (iii) protection was a function of specifically sensitized $\mathrm{CD} 8^{+} \mathrm{T}$ lymphocytes.

In cellular immunity to alphaherpesviruses, glycoproteins have been considered the primary candidates to induce a CTL response. Evidence for recognition of $\mathrm{gB}(48 ; \mathrm{H}$. Openshaw, personal communication), gC (35), and gD (48, 49) of herpes simplex virus by specific murine or human CTLs has been presented. The protective role of herpesvirus-glycoprotein-specific CTLs during herpesvirus infection in vivo is not yet clear however, although a protective effect of gD-specific $\mathrm{T}$ lymphocytes has been shown (44). Because we also detected CTLs with specificity for structural proteins $(30,31)$, the recognition of MCMV glycoproteins by a minority of CTLs is quite likely.

For several viruses, it has been documented that CTLs recognize viral proteins that are not transported to the plasma membrane to exert their specific function in viral replication. This includes structural $(2,3,9,10,40,43,46$, $47)$ and nonstructural $(3,31,38)$ viral proteins. The mode of membrane presentation of these proteins as antigens for CTL recognition is unknown. The finding that short peptides containing the relevant epitope can render cells susceptible for lysis by CTLs suggests that antigen presentation involves intracellular fragmentation of the polypeptide $(39,41)$.

Although viral proteins which are located inside the infected cell have been reported to represent target antigens for CTLs, few reports have directly addressed the question of whether these proteins could induce a protective immune response. In an early report, the protective activity of the simian virus 40 nonstructural $\mathrm{T}$ antigen against tumor formation was described (38). After vaccination with vaccinia virus recombinants expressing the nucleocapsid protein of respiratory syncytial virus and influenza virus, virus titer reduction was observed after respiratory syncytial virus challenge (16) and a certain degree of protection against mortality was observed after influenza A virus challenge (1), respectively. Similar results were obtained when the purified nucleoprotein of influenza A virus was used for immunization (45) and when CTL clones specific for the nucleoprotein were adoptively transferred (37).

In the present report, we show for the first time that structural viral proteins are not required for the induction of protective immunity against a lethal challenge with a cytolytic virus. The results, which are also supported by data published previously $(28,32-34)$, provide definite evidence that $\mathrm{T}$ lymphocytes with specificity for a single IE antigen of MCMV, the phosphoprotein pp89, control virus multiplication and can protect against lethal disease. The effector cells have the $\mathrm{CD8}^{+}$phenotype. The finding that pp89-specific antibodies induced by MCMV-ieI-VAC had neither neutralizing activity in vitro nor protected in vivo demonstrated that these antibodies did not contribute to the protection observed with MCMV-ieI-VAC. Because the antigen detected by the effector cells is expressed only after cell infection and initiation of viral gene expression, the pp89-specific CD8 ${ }^{+} \mathrm{T}$ lymphocytes cannot prevent cell infection and therefore after challenge of mice with a high dose of virus, do not prevent morbidity. They do, however, prevent mortality and aid recovery. A more effective recombinant-virus vaccine could perhaps be achieved if, in addition to the antigen required for the generation of protective CTLs, an antigen is expressed that gives rise to a neutralizing antibody response. 
There is a demand for vaccines that reduce the incidence of CMV-associated disease. Vaccines based on inactivated CMV have some protective effect $(24,26)$ but cannot induce CTLs against nonstructural proteins. On the other hand, attenuated live CMV vaccines do express the IE proteins but include the risk of viral latency and reactivation to productive cytolytic infection. The experimental vaccine described here has the advantage of inducing CTLs without any risk of establishing viral latency. Considering the central role of major histocompatibility complex glycoproteins in the presentation of antigens for recognition by $\mathrm{T}$ lymphocytes, it may appear premature to extrapolate from experimental studies in a selected mouse inbred strain to the situation in humans. Since, however, the CTL response to the ieI gene product was surprisingly dominant and because the structure and regulation of the MCMV ieI gene (14) closely resemble those of the IE1 gene of human CMV (HCMV) (36), we have predicted that the HCMV IE1 gene product should represent a major CTL antigen in HCMV infection (18). The finding that the isolated HCMV IE1 product is detected by human CTLs and indeed represents a major CTL antigen (J. G. P. Sissons and L. K. Borysiewicz, personal communication) confirms this prediction and justifies the use of MCMV infection as a model for human CMV disease.

Although the protective effect of $\mathrm{CD}^{+} \mathrm{T}$ lymphocytes is long lasting in immunocompetent hosts, it is evident that this kind of vaccination protocol will not provide protection against $\mathrm{CMV}$ infection when $\mathrm{CD8}^{+} \mathrm{T}$ lymphocytes are lost during induced or acquired immunodeficiency later on. Experiments with the murine model indicate possible alternatives. Specifically sensitized $\mathrm{CD}^{+} \mathrm{T}$ lymphocytes can be induced during the immunocompetent state, collected, and stored. Autologous cells or cells from major histocompatibility complex-compatible donors could then be adoptively transferred during the immunodepressed state. Since for some clinical situations the incidence of CMV infection is known and because studies of the cytoimmunotherapy of murine CMV disease have shown that $\mathrm{CD}^{+} \mathrm{T}$ lymphocytes can be used also for postexposure therapy $(28,32,34)$, in theory there should be no principal obstacle to specific cytoimmunotherapy of human CMV disease.

\section{ACKNOWLEDGMENTS}

We thank Anke Lüske and Irene Huber for technical assistance and Sabine Grau for preparation of the manuscript. H. Waldmann, Cambridge, England, kindly supplied the hybridoma YTS-169.4.

This work was supported by Deutsche Forschungsgemeinschaft grant Ko 571/8 and grant PTB 8614 of the Bundesministerium für Forschung und Technologie. $M$. del Val is a recipient of an Alexander von Humboldt postdoctoral fellowship.

\section{LITERATURE CITED}

1. Andrew, M. E., B. E. H. Coupar, D. B. Boyle, and G. L. Ada. 1987. The roles of influenza virus haemagglutinin and nucleoprotein in protection: analysis using vaccinia virus recombinants. Scand. J. Immunol. 25:21-28.

2. Bangham, C. R. M., P. J. M. Openshaw, L. A. Ball, A. M. Q. King, G. W. Wertz, and B. A. Askonas. 1986. Human and murine cytotoxic $T$ cells specific to respiratory syncytial virus recognize the viral nucleoprotein $(\mathrm{N})$, but not the major glycoprotein $(G)$, expressed by vaccinia virus recombinants. J. Immunol. 137:3973-3977.

3. Bennink, J. R., J. W. Yewdell, G. L. Smith, and B. Moss. 1987. Anti-influenza virus cytotoxic $\mathrm{T}$ lymphocytes recognize the three viral polymerases and a nonstructural protein: responsiveness to individual virus antigens is major histocompatibility complex controlled. J. Virol. 61:1098-1102.

4. Chalmer, J. E., J. S. Mackenzie, and N. F. Stanley. 1977.
Resistance to murine cytomegalovirus linked to the major histocompatibility complex of the mouse. J. Gen. Virol. 37:107114.

5. Cobbold, S. P., A. Jayasuriya, A. Nash, T. D. Prospero, and H. Waldman. 1984. Therapy with monoclonal antibodies by elimination of T-cell subsets in vivo. Nature (London) 312:548-551.

6. Dialynas, D. P., D. B. Wilde, P. Marrack, A. Pierres, K. A. Wall, W. Havran, G. Otten, M. R. Loken, M. Pierres, J. Kappler, and F. W. Fitch. 1983. Characterization of the murine antigenic determinant, designated L3T4a, recognized by monoclonal antibody GK 1.5: expression of L3T4a by functional T cell clones appears to correlate primarily with class II MHC antigenreactivity. Immunol. Rev. 74:29-56.

7. Dorsch-Häsler, K., G. M. Keil, F. Weber, M. Jasin, W. Schaffiner, and U. H. Koszinowski. 1985. A long and complex enhancer activates transcription of the gene coding for the highly abundant immediate early mRNA in murine cytomegalovirus. Proc. Natl. Acad. Sci. USA 82:8325-8329.

8. Ebeling, A., G. M. Keil, E. Knust, and U. H. Koszinowski. 1983. Molecular cloning and physical mapping of murine cytomegalovirus DNA. J. Virol. 47:421-433.

9. Finberg, R., D. R. Spriggs, and B. N. Fields. 1982. Host immune response to reovirus: CTL recognize the major neutralization domain of the viral hemagglutinin. J. Immunol. 129:2235-2238.

10. Holt, C. A., K. Osorio, and F. Lilly. 1986. Friend virus-specific cytotoxic $\mathrm{T}$ lymphocytes recognize both $\mathrm{gag}$ and env geneencoded specificities. J. Exp. Med. 164:211-226.

11. Jordan, M. C., and J. L. Takagi. 1983. Virulence characteristics of murine cytomegalovirus in cell and organ cultures. Infect. Immun. 41:841-843.

12. Keil, G. M., A. Ebeling-Keil, and U. H. Koszinowski. 1984. Temporal regulation of murine cytomegalovirus transcription and mapping of viral RNA synthesized at immediate early times after infection. J. Virol. 50:784-795.

13. Keil, G. M., A. Ebeling-Keil, and U. H. Koszinowski. 1987. Immediate-early genes of murine cytomegalovirus: location, transcripts, and translation products. J. Virol. 61:526-533.

14. Keil, G. M., A. Ebeling-Keil, and U. H. Koszinowski. 1987. Sequence and structural organization of murine cytomegalovirus immediate-early gene 1. J. Virol. 61:1901-1908.

15. Keil, G. M., M. R. Fibi, and U. H. Koszinowski. 1985. Characterization of the major immediate-early polypeptides encoded by murine cytomegalovirus. J. Virol. 54:422-428.

16. King, A. M. Q., E. J. Stott, S. J. Langer, K. K.-Y. Young, L. A. Ball, and G. W. Wertz. 1987. Recombinant vaccinia viruses carrying the $\mathrm{N}$ gene of human respiratory syncytial virus: studies of gene expression in cell culture and immune response in mice. J. Virol. 61:2885-2890.

17. Koszinowski, U. H., and H. Ertl. 1975. Altered serological and cellular reactivity of $\mathrm{H}-2$ antigens after target cell infection with vaccinia virus. Nature (London) 257:596-597.

18. Koszinowski, U. H., G. M. Keil, H. Schwarz, J. Schickedanz, and M. J. Reddehase. 1987. A nonstructural polypeptide encoded by immediate-early transcription unit 1 of murine cytomegalovirus is recognized by cytolytic $T$ lymphocytes. J. Exp. Med. 166: 289-294.

19. Koszinowski, U. H., G. M. Keil, H. Volkmer, M. R. Fibi, A. Ebeling-Keil, and K. Münch. 1986. The $89,000-M_{\mathrm{r}}$ murine cytomegalovirus immediate-early protein activates gene transcription. J. Virol. 58:59-66.

20. Koszinowski, U. H., M. J. Reddehase, G. M. Keil, and J. Schickedanz. 1987. Host immune response to cytomegalovirus: products of transfected viral immediate-early genes are recognized by cloned cytolytic T lymphocytes. J. Virol. 61:2054 2058.

21. Mackett, M., and G. L. Smith. 1986. Vaccinia virus expression vectors. J. Gen. Virol. 67:2067-2082.

22. Meyers, J. D. 1984. Cytomegalovirus infection following marrow transplantation: risk, treatment, and prevention. Birth Defects Orig. Artic. Ser. 20:101-117.

23. Moskovitz, L., G. T. Hensley, J. C. Chan, and K. Adams. 1985. Immediate causes of death in acquired immunodeficiency syndrome. Arch. Pathol. Lab. Med. 109:735-738. 
24. Osborn, J. E. 1981. Cytomegalovirus: pathogenicity, immunology, and vaccine initiatives. J. Infect. Dis. 143:618-630.

25. Osborn, J. E., and D. L. Walker. 1970. Virulence and attenuation of murine cytomegalovirus. Infect. Immun. 3:228-236.

26. Plotkin, S. A. 1985. CMV vaccines, p. 297-312. In B. Roizman and C. López (ed.), The herpesviruses, vol. 4. Plenum Publishing Corp., New York.

27. Quinnan, G. V., N. Kirmani, A. H. Rook, J. Manischewitz, L. Jackson, G. Moreschi, G. W. Santos, R. Saral, and W. H. Burns. 1982. HLA-restricted T-lymphocyte and non-T-lymphocyte cytotoxic responses correlate with recovery from cytomegalovirus infection in bone-marrow-transplant recipients. N. Engl. J. Med. 307:7-13.

28. Reddehase, M. J., S. Jonjić, F. Weiland, W. Mutter, and U. H. Koszinowski. 1988. Adoptive immunotherapy of murine cytomegalovirus adrenalitis in the immunocompromised host: CD4helper-independent antiviral function of CD8-positive memory $\mathrm{T}$ lymphocytes derived from latently infected donors. J. Virol. 62:1061-1065.

29. Reddehase, M. J., G. M. Keil, and U. H. Koszinowski. 1984. The cytolytic $\mathrm{T}$ lymphocyte response to the murine cytomegalovirus. I. Distinct maturation stages of cytolytic $\mathrm{T}$ lymphocytes constitute the cellular immune response during acute infection of mice with the murine cytomegalovirus. J. Immunol. 132:482489.

30. Reddehase, M. J., G. M. Keil, and U. H. Koszinowski. 1984. The cytolytic $\mathrm{T}$ lymphocyte response to the murine cytomegalovirus. II. Detection of virus replication stage-specific antigens by separate populations of in vivo active cytolytic $T$ lymphocyte precursors. Eur. J. Immunol. 14:56-61

31. Reddehase, M. J., and U. H. Koszinowski. 1984. Significance of herpesvirus immediate early gene expression in cellular immunity to cytomegalovirus infection. Nature (London) 312:369371.

32. Reddehase, M. J., W. Mutter, and U. H. Koszinowski. 1987. In vivo application of recombinant interleukin 2 in the immunotherapy of established cytomegalovirus infection. J. Exp. Med. 165:650-656.

33. Reddehase, M. J., W. Mutter, K. Münch, H.-J. Bühring, and U. H. Koszinowski. 1987. CD8-positive T lymphocytes specific for murine cytomegalovirus immediate-early antigens mediate protective immunity. J. Virol. 61:3102-3108

34. Reddehàse, M. J.; F. Weiland, K. Münch, S. Jonjic, A. Lüske, and U. H. Koszinowski. 1985. Interstitial murine cytomegalovirus pneumonia after irradiation: characterization of cells that limit viral replication during established infection of the lungs. J. Virol. 55:264-273.

35. Rosenthal, K. L., J. R. Smiley, S. South, and D. C. Johnson. 1987. Cells expressing herpes simplex virus glycoprotein $\mathrm{gC}$ but not $\mathrm{gB}, \mathrm{gD}$, or $\mathrm{gE}$ are recognized by murine virus-specific cytotoxic T lymphocytes. J. Virol. 61:2438-2447.

36. Stenberg, R. M., D. R. Thomsen, and M. F. Stinski. 1984. Structural analysis of the major immediate early gene of human cytomegalovirus. J. Virol. 49: 190-199.

37. Taylor, P. M., and B. A. Askonas. 1986. Influenza nucleoprotein-specific cytotoxic $\mathrm{T}$-cell clones are protective in vivo. Immunology 58:417-420.

38. Tevethia, S. S., D. C. Flyer, and R. Tjian. 1980. Biology of simian virus 40 (SV40) transplantation antigen ( $\mathrm{TrAg}$ ). VI. Mechanism of induction of SV40 transplantation immunity in mice by purified SV40 T antigen (D2 protein). Virology 107: 13-23.

39. Townsend, A. R. M., F. M. Gotch, and J. Davey. 1985. Cytotoxic $T$ cells recognize fragments of the influenza nucleoprotein. Cell 42:457-467.

40. Townsend, A. R. M., A. J. McMichael, N. P. Carter, J. A. Huddleston, and G. G. Brownlee. 1984. Cytotoxic T cell recognition of the influenza nucleoprotein and hemagglutinin expressed in transfected mouse L cells. Cell 39:13-25.

41. Townsend, A. R. M., J. Rothbard, F. M. Gotch, G. Bahadur, D. Wraith, and A. J. McMichael. 1986. The epitopes of influenza nucleoprotein recognized by cytotoxic $\mathrm{T}$ lymphocytes can be defined with short synthetic peptides. Cell 44:959-968.

42. Volkmer, H., C. Bertholet, S. Jonjić, R. Wittek, and U. H. Koszinowski. 1987. Cytolytic T lymphocyte recognition of the murine cytomegalovirus nonstructural immediate-early protein pp89 expressed by recombinant vaccinia virus. J. Exp. Med. 166:668-677.

43. Walker, B. D., S. Chakrabarti, B. Moss, T. J. Paradis, T. Flynn, A. G. Durno, R. S. Blumberg, J. C. Kaplan, M. S. Hirsch, and R. T. Schooley. 1987. HIV-specific cytotoxic T lymphocytes in seropositive individuals. Nature (London) 328:345-348.

44. Watari, E., B. Dietzschold, G. Szokan, and E. Heber-Katz. 1987. A synthetic peptide induces long-term protection from lethal infection with herpes simplex virus 2. J. Exp. Med. 165:459470.

45. Wraith, D. C., A. E. Vessey, and B. A. Askonas. 1987. Purified influenza virus nucleoprotein protects mice from lethal infection. J. Gen. Virol. 68:433-440.

46. Yewdell, J. W., J. R. Bennink, M. Mackett, L. Lefrancois, D. S. Lyles, and B. Moss. 1986. Recognition of cloned vesicular stomatitis virus internal and external gene products by cytotoxic T lymphocytes. J. Exp. Med. 163:1529-1538.

47. Yewdell, J. W., J. R. Bennink, G. L. Smith, and B. Moss. 1985. Influenza A virus nucleoprotein is a major target antigen of cross-reactive anti-influenza $A$ virus cytotoxic $T$ lymphocytes. Proc. Natl. Acad. Sci. USA 82:1785-1789.

48. Zarling, J. M., P. A. Moran, R. L. Burke, C. Paichl, P. W. Berman, and L. A. Lasky. 1986. Human cytotoxic T cell clones directed against herpes simplex virus-infected cells. IV. Recognition and activation by cloned glycoproteins $\mathrm{gB}$ and $\mathrm{gD}$. $\mathbf{J}$. Immunol. 136:4669-4673.

49. Zarling, J. M., P. A. Moran, L. A. Lasky, and B. Moss. 1986. Herpes simplex virus (HSV)-specific human T-cell clones recognize HSV glycoprotein D expressed by a recombinant vaccinia virus. J. Virol. 59:506-509. 